\title{
POROUS PLASTIC MATRIX TABLETS OF LEVETIRACETAM FOR ZERO-ORDER CONTROLLED RELEASE: DEVELOPMENT AND FORMULATION OPTIMIZATION
}

\author{
RAVI PARIMI*, RAMA RAO VADAPALLI, K. E. PRAVALLIKA
}

University College of Pharmaceutical Sciences, Acharya Nagarjuna University, Nagarjuna Nagar, Guntur 522510, Andhra Pradesh, India *Email: parimirv@gmail.com

Received: 20 Feb 2021, Revised and Accepted: 30 Apr 2021

\begin{abstract}
Objective: The prior objective of the current research work was to develop once-daily levetiracetam extended/controlled-release tablets having zero-order release kinetics with the plastic matrix as the release retarding element. For a high water-soluble drug, the formulation of a dosage form
\end{abstract} so as to have an extended drug release has always been a difficult task.

Methods: In the current work, levetiracetam which is a highly soluble drug was taken as the model drug for which extended-release matrix tablets were developed using varied plastic polymers like Polyvinyl acetate (PVAc), Polyvinyl chloride (PVC), Eudragit RSPO and Eudragit RLPO. PVP was considered as a pore-forming agent and PEG 6000 was taken as a water regulating agent. The porous plastic matrix tablets were prepared by embedding the drug in solvent-activated polymer dispersion followed by drying, sieving, mixing with other excipients and finally compressed. Including physical characterization studies and drug release studies, the tablets were subjected to SEM studies before and after the dissolution studies to analyze the effect of the pore former.

Results: Pre-compression mixtures exhibited good packageability of $81-92 \%$ and hence the compressed tablets were strong enough with good tensile strength in the range of $0.78-0.90 \mathrm{~N} / \mathrm{mm}^{2}$. Drug release study results showed that the drug release was controlled for a period of $12-24 \mathrm{~h}$. PVAc had shown better controlled-release among all the plastic polymers taken. PEG 6000 in combination with PVP produced the desired zeroorder drug release.

Conclusion: The levetiracetam porous plastic matrix tablets were developed with zero-order drug release that was effectively controlled for 24 hr.

Keywords: Porous plastic matrix, Pore former, Highlysoluble drugs, Zero-order controlled release, Embedding

(C) 2021 The Authors. Published by Innovare Academic Sciences Pvt Ltd. This is an open access article under the CC BY license (https://creativecommons.org/licenses/by/4.0/) DOI: https://dx.doi.org/10.22159/ijap.2021v13i4.41172. Journal homepage: https://innovareacademics.in/journals/index.php/ijap

\section{INTRODUCTION}

Developing once-daily controlled-release tablets is highly beneficial to the patient in terms of convenience of administration and reduced dosing frequency. Further, obtaining constant zero-order drug release from such tablets maintains the plasma drug concentrations in a constant manner so that tissue sensitivity is protected. Development of such dosage forms for drugs with high solubility and high dose has always been a challenge. Drugs with high solubility as well as high dose require a high amount of polymer for achieving controlled release which may greatly increase the final weight of the tablet thus causing difficulty in swallowing. Though several technologies like different matrix and reservoir systems [1-3] have been investigated to address this challenge, still there is a significant scope to investigate further especially by employing highly hydrophobic polymers like plastic matrices [4-6]. Adequate literature published the use of plastic polymers like Eudrgait and other hydrophobic matrices to attain the controlled release drug release some of them include were by Apurba Sarker Apu et al. [7]; $\mathrm{H}$ Tabandeh et al. [8]; Sarika Pundir et al. [9]; and Sudarshan Singh et al. [10]. But, in all this literature works the final weight of the tablets were more than $1000 \mathrm{mg}$ and also drug release was completed well before $24 \mathrm{~h}$. Hence, there is a need to develop controlled release matrix tablets for drugs with a high dose to prolong the drug release for $24 \mathrm{~h}$ and also to restrict the final weight of the tablet.

Levetiracetam (LVT) is a BCS Class I drug possessing high solubility of $1040 \mathrm{mg} / \mathrm{ml}$ and of $1000 \mathrm{mg}$ as starting dose used in the treatment of epilepsy [11]. The high dose as well as high solubility of LVT resulting in the formulation of a larger size tablet is a major drawback of the formulation of this drug. Hence, LVT is selected as the model drug in this research work, so as to overcome these problems associated with the formulation.

Hence, in the current research, it was aimed to develop once daily controlled release matrix tablets of possible less final weight/size with constant zero-order drug release for a high water-soluble and high dose drug by taking Levetiracetam as a model drug. This was further aimed to achieve by using plastic matrices viz. Eudragit RSPO, Eudragit RLPO, polyvinyl acetate and polyvinyl chloride combined with a pore former PVP K15 [12] and water regulating agent PEG 6000 regarding which a very little literature suggested the possibility of their exploration for developing controlled release porous matrix tablets with the zero-order release.

\section{MATERIALS AND METHODS}

\section{Materials}

The API, Levetiracetam was obtained as a gift sample from Hetero Drugs Pvt. Ltd., Hyderabad; polyvinyl acetate, polyvinyl chloride, Eudragit RLPO and RSPO, PVP K15 (low viscosity grade) and PEG 6000 were procured from Sigma Aldrich, Mumbai; Magnesium stearate and talc were procured from Loba Chemie Ltd, Hyderabad.

\section{Drug-excipient compatibility studies}

Fourier Transform Infrared (FT-IR) spectroscopy was used to study the compatibility between LVT and the polymers. Pure LVT and mixtures of LVT with the polymers at maximum weight ratios as per the formulae were prepared as pellets in a hydraulic press after mixing with $\mathrm{KBr}$. In a wavelength range of 400 to $4000 \mathrm{~cm}^{-1}$, each pellet was studied by FT-IR spectroscopy and an average of 16 scans of the spectrum was taken. The pure drug spectrum was then compared with the spectrum of the physical mixtures.

\section{Preparation of plastic matrix tablets of LVT}

As per the formulae (table 1), required quantities of plastic polymers were dissolved in acetone to attain a dispersion with semisolid consistency. Pre-determined quantity of LVT and PG 6000 were embedded [13] in the above mixture with vigorous mixing which 
was then subjected to drying. This LVT embedded plastic dispersion was sieved through \#20 sieve to obtain plastic matrix granules which are further mixed with PVP K15, magnesium stearate and talc. The blend was then compressed using $12 \mathrm{~mm}$ punch to obtain flatfaced round elegant tablets [14].

\section{Characterization studies for the pre-compression mixture}

The plastic matrix granules of all the formulations were subjected to different evaluation studies [10] viz. bulk density, tapped density, Carr's index, Hausner's ratio and angle of repose in order to assure their suitability for compression into tablets.
Characterization studies for the compressed plastic matrix tablets of LVT

\section{Tensile strength}

The tensile strength is the stress required to break a tablet indicating the tablet's physical strength. Vernier caliper was used to measure the thickness ( $t$ ) and diameter (D) of the tablet. Monsanto hardness tester was used to determine the hardness or crushing strength $\left(\mathrm{F}_{\mathrm{c}}\right)$. Tensile strength was calculated using the following equation [15].

$$
\mathrm{T}=\frac{2 \mathrm{~F}_{\mathrm{c}}}{\pi \mathrm{Dt}}
$$

Table 1: Compositions of various formulations of porous plastic matrix tablets of LVT

\begin{tabular}{|c|c|c|c|c|c|c|c|c|c|c|c|c|c|c|c|c|}
\hline \multirow[t]{2}{*}{ Ingredient } & \multicolumn{16}{|c|}{ Quantity in mg per one tablet } \\
\hline & $\begin{array}{l}\text { ERL } \\
\text { F1 }\end{array}$ & $\begin{array}{l}\text { ERL } \\
\text { F2 }\end{array}$ & $\begin{array}{l}\text { ERL } \\
\text { F3 }\end{array}$ & $\begin{array}{l}\text { ERL } \\
\text { F4 }\end{array}$ & $\begin{array}{l}\text { ERS } \\
\text { F1 }\end{array}$ & $\begin{array}{l}\text { ERS } \\
\text { F2 }\end{array}$ & $\begin{array}{l}\text { ERS } \\
\text { F3 } \\
\end{array}$ & $\begin{array}{l}\text { ERS } \\
\text { F4 }\end{array}$ & PVAcF1 & $\begin{array}{l}\text { PVAc } \\
\text { F2 }\end{array}$ & $\begin{array}{l}\text { PVAc } \\
\text { F3 }\end{array}$ & $\begin{array}{l}\text { PVAc } \\
\text { F4 }\end{array}$ & $\begin{array}{l}\text { PVC } \\
\text { F1 }\end{array}$ & $\begin{array}{l}\text { PVC } \\
\text { F2 }\end{array}$ & $\begin{array}{l}\text { PVC } \\
\text { F3 }\end{array}$ & $\begin{array}{l}\text { PVC } \\
\text { F4 }\end{array}$ \\
\hline Levetiracetam & 500 & 500 & 500 & 500 & 500 & 500 & 500 & 500 & 500 & 500 & 500 & 500 & 500 & 500 & 500 & 500 \\
\hline Eudragit RLPO & 150 & 150 & 150 & 200 & - & - & - & - & - & - & - & - & - & - & - & - \\
\hline Eudragit RSPO & - & - & - & - & 150 & 150 & 150 & 200 & - & - & - & - & - & - & - & - \\
\hline $\begin{array}{l}\text { Polyvinyl } \\
\text { acetate }\end{array}$ & - & - & - & - & - & - & - & - & 150 & 150 & 150 & 200 & - & - & - & - \\
\hline $\begin{array}{l}\text { Polyvinyl } \\
\text { chloride }\end{array}$ & - & - & - & - & - & - & - & - & - & - & - & - & 150 & 150 & 150 & 200 \\
\hline PEG 6000 & - & 50 & 60 & - & - & 50 & 60 & - & - & 50 & 60 & - & - & 50 & 60 & - \\
\hline PVP & 75 & 25 & 15 & 25 & 75 & 25 & 15 & 25 & 75 & 25 & 15 & 25 & 75 & 25 & 15 & 25 \\
\hline Lubricant & 10 & 10 & 10 & 10 & 10 & 10 & 10 & 10 & 10 & 10 & 10 & 10 & 10 & 10 & 10 & 10 \\
\hline Glidant & 10 & 10 & 10 & 10 & 10 & 10 & 10 & 10 & 10 & 10 & 10 & 10 & 10 & 10 & 10 & 10 \\
\hline Total & 745 & 745 & 745 & 745 & 745 & 745 & 745 & 745 & 745 & 745 & 745 & 745 & 745 & 745 & 745 & 745 \\
\hline
\end{tabular}

\section{Packing fraction and porosity}

The degree of consolidation of tableting powder after compression is known as the packing fraction. It was calculated using the equation [16]

$$
\mathrm{P}_{\mathrm{f}}=\frac{\mathrm{w}}{\pi \mathrm{r}^{2} \mathrm{t} \rho}
$$

where $w$ is the weight of tablet; $r$ and $t$ are radius and thickness of the tablet; and $\rho$ is the true density of the tableting powder. Liquid displacement method using liquid paraffin was used to determine the true density of the tableting powder. The porosity indicates the degree of penetration of water into the tablet which is obtained by subtracting the packing fraction form 1 .

\section{Friability}

Roche friabilator was used to determine the friability [17] in which 10 tablets were rotated at a speed of $25 \mathrm{rpm}$ for $4 \mathrm{~min}$. so as to complete 100 revolutions. The tablets were then removed, dedusted and weighed. From the combined weights of tablets before $\left(\mathrm{w}_{1}\right)$ and after ( $\mathrm{w}_{2}$ ) friabilation, \% friability was calculated using the equation

$$
\% \text { friability }=\frac{\mathrm{w}_{1}-\mathrm{w}_{2}}{\mathrm{w}_{1}} \times 100
$$

\section{Drug content}

$100 \mathrm{mg}$ drug equivalent powder of the tablets powder was taken and added into water (as the LVT is freely water-soluble) and subjected to intense mixing ensuring dissolution of LVT. The mixture was then filtered and diluted in a $100 \mathrm{ml}$ volumetric flask. After necessary dilutions, the filtrate was analyzed using a UV-Visible spectrophotometer at its maximum wavelength of $194 \mathrm{~nm}$ [18].

\section{Drug release studies}

The prepared LVT plastic matrix tablets were subjected to drug release studies according to the USFDA specified dissolution conditions [16]. In basket (USP type I) apparatus at $100 \mathrm{rpm}, 900 \mathrm{ml}$ of $0.05 \mathrm{M}$ phosphate buffer $\mathrm{pH} 6.0$ was taken as the dissolution medium. At various time intervals, $5 \mathrm{ml}$ of samples were taken and replaced with fresh buffer. After suitable dilutions, the collected samples were analyzed at a maximum wavelength of $194 \mathrm{~nm}$ using a UV-Visible spectrophotometer.

\section{Drug release kinetic studies}

To determine the order of drug release kinetics and the mechanism of drug release from the developed LVT plastic matrix tablets, the data obtained from the drug release studies were fitted to various kinetic models [19]. Zero-order, first-order, Higuchi's and Korsmeyer-Peppas models the kinetic models employed to fit the data were.

\section{SEM studies}

The surface morphology of the formulated tablet was observed before and after subjecting to the drug release studies by carrying the scanning electron microscopy studies [19] to assess the effectiveness of the pore former used.

\section{Statistical analysis}

Different formulation variables were viz. type of plastic polymer, amount of the polymer, amount of pore former so as to achieve constant drug release for $24 \mathrm{~h}$. The results of drug release studies were subjected to ANOVA test to investigate whether the effect of different formulation variables taken in this work on drug release rate was significant or not.

\section{RESULTS AND DISCUSSION}

\section{Drug-excipient compatibility studies}

The IR spectrum of pure LVT was compared with the spectra of its physical mixtures with the selected plastic materials (shown in fig. 1). The characteristic peaks corresponding to the characteristic functional groups of LVT observed in the spectrum of the pure drug were $\mathrm{N}-\mathrm{H}$ stretching at $3359 \mathrm{~cm}^{-1} ; \mathrm{C}-\mathrm{H}$ stretching at $2895 \mathrm{~cm}^{-1} ; \mathrm{C}=\mathrm{O}$ bending at $1674 \mathrm{~cm}^{-1} ; \mathrm{C}-\mathrm{H}$ bending at $1430 \mathrm{~cm}^{-1}$; C-N stretching at $1084 \mathrm{~cm}^{-1}[16]$. The same peaks at and close to these wavenumbers were also observed in the spectra of physical mixtures of LVT with all the polymers. This indicated the absence of incompatibilities between LVT and the selected plastic polymers, PVP K15 and PEG 6000 thus permitting their use in LVT plastic matrix tablets. 

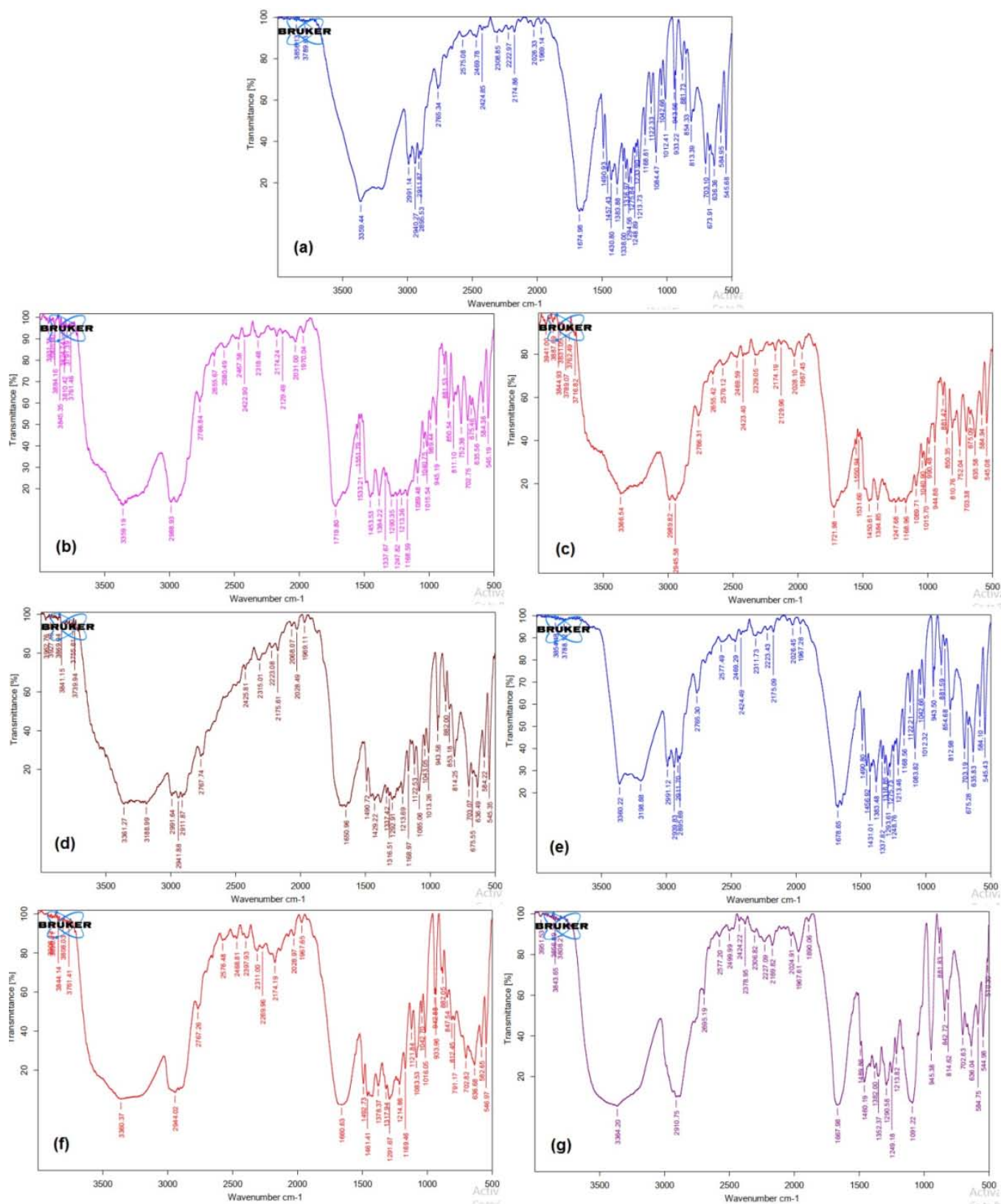

Fig. 1: FT-IR spectra of pure LVT and physical mixtures of LVT with different polymers. (a) Pure LVT; (b) LVT+Eudragit RLPO; (c) LVT+Eudragit RLPO; (d) LVT+PVAc; (e) LVT+PVC; (f) LVT+PVP and (g) LVT+PEG 6000

\section{Characterization studies for the pre-compression mixture}

Prior to tapping, the bulk density of all the formulations was found to be in the range of $0.50-0.52 \mathrm{~g} / \mathrm{ml}$ and after tapping, it was found to be in the range of $0.57-0.60 \mathrm{~g} / \mathrm{ml}$. A good compressibility and package ability for table ting of the plastic matrix granules has been inferred from the difference in bulk densities before and after tapping. A range of 1.16-1.13 and 13.56-11.48 were observed for the Hausner's ratio and Carr's index respectively. Angle of repose values were found to be in the range of $12.51-14.76^{\circ}$ and all the results indicated good to excellent flow properties and hence could be effectively compressed into tablets.

\section{Preparation of plastic matrix tablets of LVT}

The plastic matrix tablets were prepared by dispersing the drug and PEG 6000 mixture into Eudragit RLPO/Eudragit RSPO/PVAc/PVC matrix followed by mixing with PVP K15 and other excipients and finally compressed into flat-faced tablets of $12 \mathrm{~mm}$ diameter. The embedment of the drug into the solvent-activated plastic matrix made effective incorporation of the drug into the matrix would result in relatively less amount of rate retardant material sufficient to achieve desired control release when compared to simple physical mixing of drug and polymer. This would reduce the weight of the final tablet, which is the prior and substantial advantage especially for high-dose drugs like LVT.

\section{Physical characterization studies}

\section{Tensile strength}

All the formulations of the LVT plastic matrix tablets were compressed using punches of $12 \mathrm{~mm}$ diameter and an adjusted thickness of $5.5 \mathrm{~mm}$. The compressed tablets were found to have hardness in the range of 8.2-9.5 kilogram-force (kgf), therefore showing the tensile strength values in the range of $0.78-0.90 \mathrm{~N} / \mathrm{mm}^{2}$ as shown in the table 2 . The high hardness and tensile strength values obtained indicated the good physical strength of tablets and the selected plastic polymers and their mode of use for the development of matrix tablets. 


\section{Packing fraction}

The packing fraction is dependent on the nature of the material to be compressed besides particle size. The higher packing fraction indicates greater efficiency of tableting and thereby greater strength of the tablets [15]. The values of this packing fraction for all the formulations of plastic matrix tablets of LVT were found to be in the range of 0.81-0.92indicating that all the formulations had good tableting efficiency thus suitable for compression into tablets. The residual porosity of the tablets was obtained by subtracting the packing fraction from 1 and these values are ranging from 0.08-0.19 (table 2). This little porosity is necessary for enabling the drug release from the plastic matrix tablets by penetration of water.

\section{Friability}

Friability gives the needed evidence for the strength of plastic matrix tablets. The $\%$ friability values for all the formulation varied in the range of $0.40-0.52 \%$ (table 2). The obtained values indicated the developed tablets were adequately strong to overcome the forces that might occur during handling, packing and transportation.

\section{Drug release studies}

The prepared LVT plastic matrix tablets of LVT were subjected to drug release studies according to USFDA dissolution specifications. The dissolution profiles in the form of zero-order plots for tablets of all plastics were shown in fig. 2 to fig. 5 .

Table 2: Results of different physical characterization studies of porous plastic matrix tablets of LVT

\begin{tabular}{|c|c|c|c|c|c|}
\hline S. No. & Formulation & Tensile strength $\left(\mathrm{N} / \mathrm{mm}^{2}\right)$ & Packing fraction $\left(P_{f}\right)$ & Porosity fraction $\left(1-P_{f}\right)$ & Friability (\%) \\
\hline 1 & ERLF1 & $0.85 \pm 0.01$ & $0.83 \pm 0.01$ & $0.17 \pm 0.02$ & $0.51 \pm 0.02$ \\
\hline 2 & ERLF2 & $0.87 \pm 0.03$ & $0.88 \pm 0.02$ & $0.12 \pm 0.03$ & $0.46 \pm 0.05$ \\
\hline 3 & ERLF3 & $0.89 \pm 0.02$ & $0.86 \pm 0.03$ & $0.14 \pm 0.01$ & $0.56 \pm 0.04$ \\
\hline 4 & ERLF4 & $0.88 \pm 0.03$ & $0.91 \pm 0.01$ & $0.09 \pm 0.03$ & $0.52 \pm 0.03$ \\
\hline 5 & ERSF1 & $0.82 \pm 0.01$ & $0.84 \pm 0.03$ & $0.16 \pm 0.04$ & $0.54 \pm 0.05$ \\
\hline 6 & ERSF2 & $0.85 \pm 0.02$ & $0.89 \pm 0.02$ & $0.11 \pm 0.02$ & $0.47 \pm 0.04$ \\
\hline 7 & ERSF3 & $0.87 \pm 0.01$ & $0.86 \pm 0.04$ & $0.14 \pm 0.03$ & $0.50 \pm 0.02$ \\
\hline 8 & ERSF4 & $0.80 \pm 0.02$ & $0.90 \pm 0.03$ & $0.10 \pm 0.01$ & $0.42 \pm 0.06$ \\
\hline 9 & PVAcF1 & $0.85 \pm 0.03$ & $0.83 \pm 0.02$ & $0.17 \pm 0.01$ & $0.46 \pm 0.04$ \\
\hline 10 & PVAcF2 & $0.83 \pm 0.02$ & $0.82 \pm 0.01$ & $0.18 \pm 0.02$ & $0.45 \pm 0.02$ \\
\hline 11 & PVAcF3 & $0.82 \pm 0.03$ & $0.90 \pm 0.01$ & $0.10 \pm 0.02$ & $0.44 \pm 0.03$ \\
\hline 12 & PVAcF4 & $0.80 \pm 0.01$ & $0.81 \pm 0.02$ & $0.09 \pm 0.04$ & $0.42 \pm 0.05$ \\
\hline 13 & PVCF1 & $0.79 \pm 0.01$ & $0.85 \pm 0.03$ & $0.15 \pm 0.03$ & $0.48 \pm 0.02$ \\
\hline 14 & PVCF2 & $0.81 \pm 0.02$ & $0.92 \pm 0.02$ & $0.18 \pm 0.03$ & $0.45 \pm 0.03$ \\
\hline 15 & PVCF3 & $0.84 \pm 0.03$ & $0.91 \pm 0.01$ & $0.09 \pm 0.02$ & $0.41 \pm 0.04$ \\
\hline 16 & PVCF4 & $0.80 \pm 0.02$ & $0.87 \pm 0.03$ & $0.13 \pm 0.01$ & $0.44 \pm 0.05$ \\
\hline
\end{tabular}

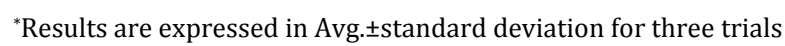

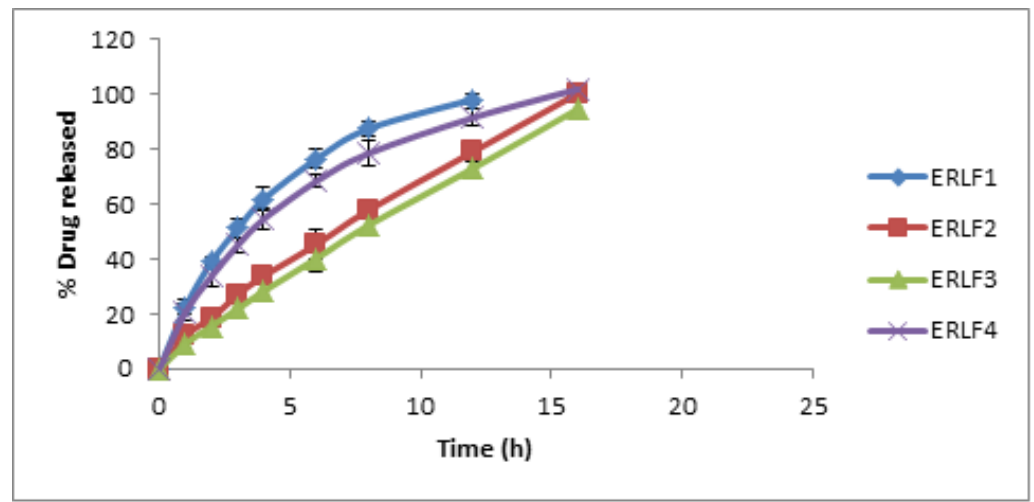

* Error bars represent standard deriation for $n=3$

Fig. 2: Zero-order plots of drug release of tablets prepared with eudragit RLPO

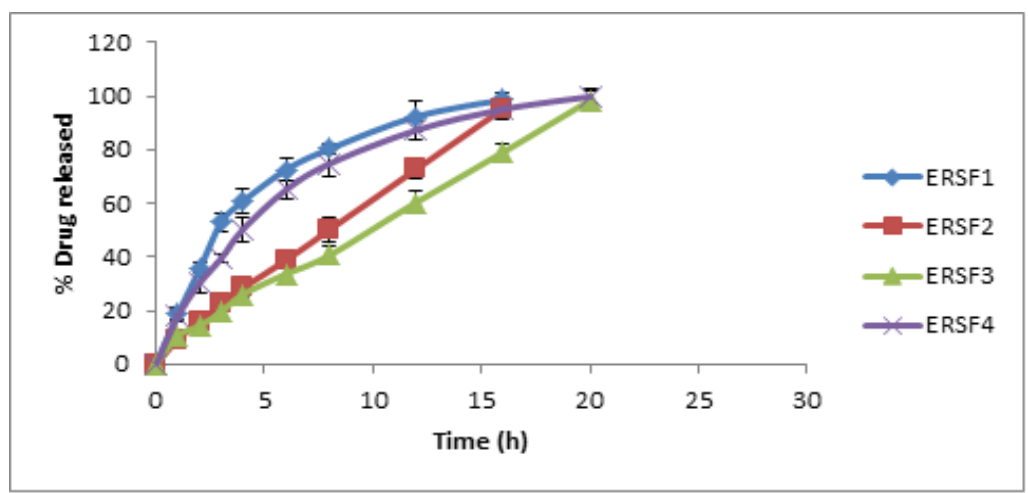

* Error bars represent standard deviation for $n=3$

Fig. 3: Zero-order plots of drug release of tablets prepared with Eudragit RSPO 


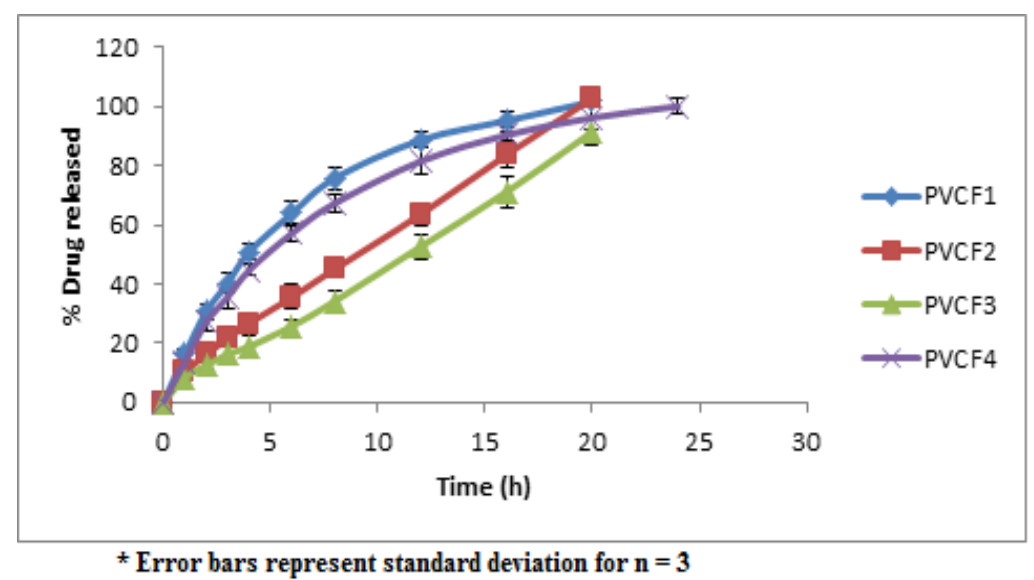

Fig. 4: Zero-order plots of drug release of tablets prepared with Polyvinyl chloride

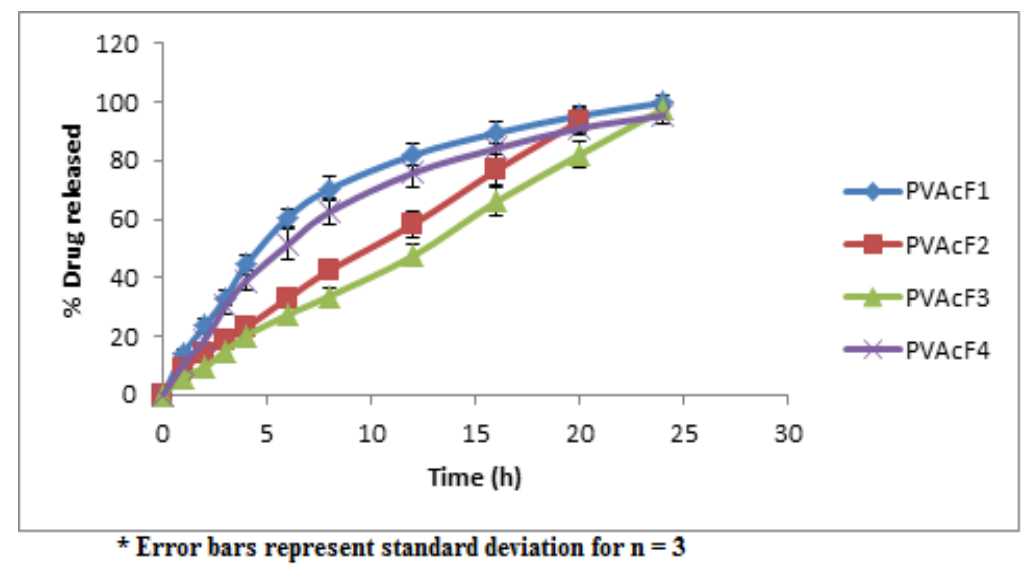

Fig. 5: Zero-order plots of drug release of tablets prepared with polyvinyl acetate

In the formulation of plastic matrix tablets, the materials responsible for drug release were plastic polymers, PEG 6000 and PVP K15. The plastic polymers are highly hydrophobic and have a very low water permeability favoring the controlled release of the drug. PEG 6000 is a hydrophilic and slowly soluble polymer that effectively regulates the availability of water inside the plastic matrix. PVP K15 is a low viscous, highly and readily water-soluble material thereby readily dissolved when added to the dissolution medium forming pores on the plastic matrix tablet favoring the drug release.
After several trials of each plastic polymer, four formulations were developed in order to study the effect of amounts of plastic polymer, PEG 6000 and PVP. The first three formulations containing $150 \mathrm{mg}$ and the fourth formulation containing $250 \mathrm{mg}$ of plastic with varying amounts of PEG 6000 and PVP. The effect of the amounts of plastic and PVP without the influence of PEG 6000, for every plastic polymer taken, can be understood by comparing formulations F1 and F4. The effect of PEG 6000 can be understood by comparing formulations F2 and F3.

Table 3: Results of drug release kinetic studies of porous plastic matrix tablets of LVT

\begin{tabular}{|c|c|c|c|c|c|c|c|}
\hline \multirow[t]{2}{*}{ S. No. } & \multirow[t]{2}{*}{ Formulation } & \multicolumn{3}{|c|}{ Regression $\left(\mathrm{R}^{2}\right)$ values } & \multirow{2}{*}{$\begin{array}{l}\text { Zero-order rate } \\
\text { constant }(\% / h)\end{array}$} & \multirow{2}{*}{$\begin{array}{l}\text { First-order rate } \\
\text { constant }\left(h^{-1}\right)\end{array}$} & \multirow{2}{*}{$\begin{array}{l}\text { Peppas ' } n \\
\text { values }\end{array}$} \\
\hline & & Zero-order & First-order & Higuchi's & & & \\
\hline 1 & ERLF1 & 0.715 & 0.958 & 0.986 & -- & 0.295 & 0.597 \\
\hline 2 & ERLF2 & 0.971 & 0.77 & 0.918 & 6.707 & -- & 0.771 \\
\hline 3 & ERLF3 & 0.99 & 0.975 & 0.887 & 6.17 & -- & 0.851 \\
\hline 4 & ERLF4 & 0.695 & 0.997 & 0.989 & -- & 0.2 & 0.576 \\
\hline 5 & ERSF1 & 0.566 & 0.973 & 0.966 & -- & 0.237 & 0.58 \\
\hline 6 & ERSF2 & 0.991 & 0.839 & 0.883 & 6.143 & -- & 0.839 \\
\hline 7 & ERSF3 & 0.986 & 0.748 & 0.89 & 5.043 & -- & 0.763 \\
\hline 8 & ERSF4 & 0.646 & 0.996 & 0.979 & -- & 0.18 & 0.577 \\
\hline 9 & PVAcF1 & 0.675 & 0.996 & 0.97 & -- & 0.148 & 0.619 \\
\hline 10 & PVAcF2 & 0.987 & 0.878 & 0.896 & 4.867 & -- & 0.794 \\
\hline 11 & PVAcF3 & 0.996 & 0.933 & 0.87 & 4.118 & -- & 0.878 \\
\hline 12 & PVAcF4 & 0.768 & 0.996 & 0.973 & -- & 0.122 & 0.689 \\
\hline 13 & PVCF1 & 0.662 & 0.997 & 0.979 & -- & 0.184 & 0.599 \\
\hline 14 & PVCF2 & 0.985 & 0.759 & 0.898 & 5.32 & -- & 0.774 \\
\hline 15 & PVCF3 & 0.994 & 0.951 & 0.847 & 4.504 & -- & 0.81 \\
\hline 16 & PVCF4 & 0.685 & 0.991 & 0.981 & -- & 0.152 & 0.607 \\
\hline
\end{tabular}




\section{Effect of type of plastic polymer}

The efficiency of plastic polymers taken in this research work to control the release of drug was found to be highest for Eudragit RLPO and lowest for polyvinyl acetate in the order of Eudragit RLPO $>$ Eudragit RSPO $>$ Polyvinylchloride $>$ Polyvinyl acetate. The effect of type of plastic polymer on the drug release rate was found to be significant $(p<0.05$, one-way ANOVA). The rate constant values were showed in the table 3 . This could be attributed to the degree of permeability of water by the polymer into the plastic polymer matrix [21-23]. With the increase in the permeability of water into the plastic matrix, the diffusion of the drug from the plastic matrix increases and vice versa.

\section{Effect of amount of plastic polymers}

It was evident from the formulations F1 and F4 that with the increase in the concentration of the plastic polymer, the drug release rate was found to be significantly decreased $(p<0.05$, one-way ANOVA) due to the increase in the density of the plastic polymer as well as owing to the difficulty in permeation of water into the plastic matrix at high amounts of the matrix polymers. The obtained results were correlated with those reported by Maskova E et al. [23].

\section{Effect of amount of PEG 6000}

A significant effect of PEG was found on the drug release rate $(p<0.05$, one-way ANOVA) and also the drug release kinetics (table 3). In case of every plastic polymer, formulations without PEG 6000 in F1 and F4 have shown first-order kinetics of drug release and F2 and F3 containing PEG 6000 have shown zero-order drug release kinetics. This could be attributed to the ability of PEG 6000 to maintain the availability of water inside the matrix constantly that could alter the drug release $[24,25]$ and the insoluble, non-swellable as well as non-erodible plastic matrix could maintain the constant geometry of the tablet achieved constant zero-order drug release.

\section{Effect of amount of PVP K15}

PVP K15 was employed in this study as a pore former which allows access of water into the plastic matrix tablet upon its addition into aqueous medium and hence drug release would be started without much lag time. The amount of PVP K15 showed a significant ( $<<0.05$, one-way ANOVA) effect on drug release by comparing the formulations F1 and F4 as well as F2 and F3 in the case of every plastic matrix. The higher amount of PVP K15 in in F1 made the drug release rapid when compared to that of F4. Similarly, formulation F2 showed higher release rate when compared to that of F3, which could be attributed to the presence of higher amount of PVP K15 in F2 than in F3. High amount of poreformer PVP could create more pores in the plastic matrix tablet which could permeate more amount of water thus allowing more amount of drug release [26, 27].

This amount of pore former along with PEG 6000 was found to be critical in identifying the formulation with desired drug release profile. Formulations F2 and F3 in case of every plastic polymer showed zeroorder drug release and the release was more controlled in case of F3 formulations when compared to those of F2 formulations. Further, formulation F2 with relatively less amount of PEG 6000 and more amount of pore former could show a maximum control of drug release up to $20 \mathrm{hr}$ only which was in case of PVAc matrix. Whereas formulation F3 in case of PVAc showed constant zero-order drug release up to $24 \mathrm{hr}$ and hence the set objective of the work was achieved by this porous matrix tablets of formulation PVAcF3.

\section{Drug release kinetic studies}

The Higuchi's and Korsmeyer-Peppas plots were used to study the mechanism of drug release and the results were shown in table 3. In every plastic polymer, the formulations, F1 and F4 have shown more Higuchi's regression values and lesser Korsemeyer-Peppas coefficients than those of their corresponding F2 and F3 formulations. This elucidated that the drug release was majorly by diffusion in F1 and F4 formulations. Whereas, in case of F2 and F3 formulations, higher Korsemeyer-Peppas coefficients and low Higuchi's regression values indicated thenon-Fickiandiffusion of drug release that is diffusion by boundary effect and pores. This could be attributed to the presence of PEG 6000 in the formulations F2 and F3. During the time of drug release, zero-order release from these F2 and F3 formulations was obtained as the boundary effect and pores were constant.

\section{SEM studies}

The porous structure of the matrix tablet (of formulation PVAcF3) after drug release study was observed in comparison with the tablet surface before subjecting to the drug release study by SEM studies (fig. 6). The results of SEM studies clearly illustrated the formation of pores which might be because of the pore former PVP K15, which could modify the permeability of water into the matrix thus aid in achieving desired drug release profile.

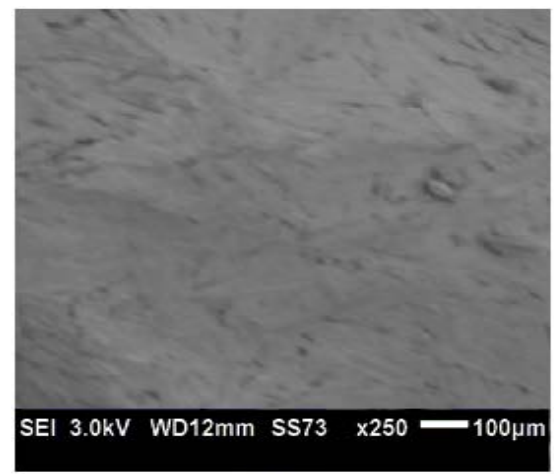

(a)

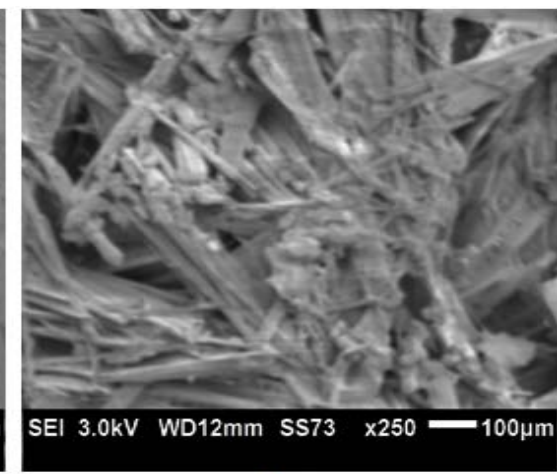

(b)

Fig. 6: SEM images of porous plastic matrix tablets (a) Before drug release study (b) After drug release study

\section{CONCLUSION}

This work was carried to develop a single daily dose, controlled release tablet of LVT with constant zero-order drug release and also with minimum possible final weight. With variable amounts of PEG 6000 as water content regulator and PVP as pore former in the matrix, the LVT plastic matrix tablets were developed. A zero-order release of drug from the plastic matrix tablets can be obtained in tablets with PEG 6000 i.e. formulations F2 and F3 in the case of each plastic polymer. The drug release from the plastic matrix tablets was found to follow zero-order release and controlled for $24 \mathrm{~h}$ in the case of PVAc matrix which was found to be more effective among all the studied polymers in this study and also when compared to the Levetiracetum tablets prepared by Sudarshan Singh et al. [12] whose drug release was controlled for about $18 \mathrm{~h}$ only and also the final weight of the tablet was $1100 \mathrm{mg}$. which was very higher than the final weight of $745 \mathrm{mg}$ in the current study. Hence, the desired zero-order control release with high release retardation and lower weight of the final tablet has been achieved successfully through the formulation of porous plastic matrix tablets in this research work. 


\section{ACKNOWLEDGEMENT}

The authors are acknowledged to the authority of Acharya Nagarjuna University for providing the necessary facilities and support to carry out this research work.

\section{FUNDING}

Nil

\section{AUTHORS CONTRIBUTIONS}

All the authors have contributed equally.

\section{CONFLICTS OF INTERESTS}

Declared none

\section{REFERENCES}

1. Mondal N. The role of matrix tablet in drug delivery system. Int J Appl Pharm 2018;10:1-6.

2. Patel H, Panchal DR, Patel U, Brahmbhatt T, Suthar M. Matrix type drug delivery system: a review. J Pharm Sci Bio-Sci Res 2011;1:143-51.

3. Reza MS, Quadi MA, Haider SS. Comparative evaluation of plastic, hydrophobic and hydrophilic polymers as matrices for controlled-release drug delivery. J Pharm Pharm Sci 2003;6:282-91.

4. Shammika P, Aneesh TP, Vidya Viswanad. Formulation and evaluation of synthesized quinazolinone derivative for colon specific drug delivery. Asian J Pharm Clin Res 2017;10:207-12.

5. Arafat M. Approaches to achieve an oral controlled release drug delivery system using polymers: a recent review. Int J Pharm Pharm Sci 2015;7:16-21.

6. Rajesh K, Deveswaran R, Bharath S, Basavaraj BV. Development of mesalazine microspheres for colon targeting. Int J Appl Pharm 2017;9:1-9.

7. Apu AS, Pathan AH, Shrestha D, Kibria G, Jalil R. Investigation of in vitro release kinetics of carbamazepine from Eudragit RSPO and RLPO matrix tablets. Trop J Pharm Res 2009;8:145.

8. Tabandeh H, Mortazavi SA, Guilani TB. Preparation of sustained-release matrix tablets of aspirin with ethylcellulose, Eudragit RS100 and Eudragit S100 and studying the release profiles and their sensitivity to tablet hardness. Iran J Pharm Sci 2003;2:201-6.

9. Pundir S, Badola A, Sharma D. Sustained release matrix technology and recent advance in matrix drug delivery system: a review. Int J Drug Res Tech 2013;3:12-20.

10. Singh S, Bhavesh S, Sanjaykumar N, Sunil B. Formulation and evaluation of levetiracetam extended-release tablets. Int J Pharm Sci Nanotech 2003;6:1958-65.

11. Eerike M, Konda VGR, Arunachalam R, Dawood U. Evaluation of antiepileptic activity of ethanolic extract of Azimatetracantha root in mice. Int J Curr Pharm Res 2016;8:76-9.
12. Alhalmi A, Altowairi M, Saeed O, Alzubaidi N, Almoiliqy M, Abdulmalik W. Sustained release matrix system: an overview. World J Pharm Pharm Sci 2018;7:1470-86.

13. Srikar G, Avula P, Koreddi S. Embedment technique: an alternative to wet granulation for bettercontrol of release of highly water-soluble drugs-a case study with diltiazem $\mathrm{HCl}$. IntJ Pharm Pharm Sci 2015;7:270-6.

14. Karvekar M, Khan AB. A brief review on sustained-release matrix-type drug delivery system. J Pharm Res 2017;16:282-9.

15. Mohammed SS. Preparation, characterization and preformulation studies of diltiazem sustain release tablet. Asian J Res Pharm Sci Biotechnol 2014;2:16-22.

16. Chavan PM, Ughade S. Preparation, characterization and evaluation of tablet for colonic delivery. Int J Pharm Sci Res 2018;9:2027-33.

17. Eichie FE, Kudehinbu AO. Effect of particle size of granules on some mechanical properties of paracetamol tablets. Afr J Biotechnol 2009;8:5913-6.

18. Zaid AN, Al-Ramahi RJ, Ghoush AA, Qaddumi A, Zaroor YA. Weight and content uniformity of lorazepam half tablets: a study of correlation of low drug content product. Saudi Pharm J 2013;21:71-5.

19. Vijaya Durga K, Ashok Kumar P, Kulkarni SV. Influence of natural, synthetic polymers and fillers on sustained release matrix tablets of pregabalin. Int J Drug Dev Res 2013;5:252-67.

20. S Sivaneswari, E Karthikeyan, PJ Chandana. Novel expandable gastro retentive system by unfolding mechanism of levetiracetam using simple lattice design-formulation optimization and in vitro evaluation. Bull Fac Pharm Cairo Univ 2017;55:63-72.

21. Row RC, Shesky PJ, Owen SC. editors. Handbook of pharmaceutical excipients. London: Pharmaceutical Press; 2006.

22. Keller PE, Kouzes R. Water vapor permeation in plastics. Pacific Northwest National Laboratory: Washington; 2007.

23. Maskova E, Naiserova M, Kubova K, Masek J, Pavlokovs S, Urbanova $\mathrm{M}$, et al. Highly soluble drugs directly granulated by water dispersions of insoluble Eudragit polymers as a part of hypromellose K100M matrix systems. BioMed Res Int 2019. https://doi.org/10.1155/2019/8043415

24. D'souza AA, Shegokar R. Polyethylene glycol (PEG): a versatile polymer for pharmaceutical applications. Expert Opin Drug Delivery 2016;13:1257-75.

25. Robinson JR, Lee VHL. editors. Controlled drug deliveryfundamentals and applications. New York: Informa Healthcare; 2011.

26. Yang M, Xie S, Li Q, Wang Y, Chang X, Shan L, et al. Effects of polyvinylpyrrolidone both as a binder and pore-former on the release of sparingly water-soluble topiramate from ethylcellulose coated pellets. Int J Pharm 2014;465:187-96.

27. Hwang JR, Sefton MV. The effects of polymer concentration and a pore-forming agent (PVP) on HEMA-MMA microcapsule structure and permeability. J Membr Sci 1995;108:257-68. 